ENCYCLOPÉDIE Encyclopédie berbère

BERBERE

3 | 1986

3 | Ahaggar - Alī ben Ghaniya

\title{
Ain SefraA122. AIN SEFRA
}

G. Camps

\section{OpenEdition}

Journals

Édition électronique

URL : http://journals.openedition.org/encyclopedieberbere/842

DOI : $10.4000 /$ encyclopedieberbere.842

ISSN : 2262-7197

\section{Éditeur}

Peeters Publishers

\section{Édition imprimée}

Date de publication : 1 juillet 1986

Pagination : 338-340

ISBN : 2-85744-260-2

ISSN : 1015-7344

\section{Référence électronique}

G. Camps, «Ain SefraA122. AIN SEFRA », Encyclopédie berbère [En ligne], 3 | 1986, document A122, mis en ligne le 01 décembre 2012, consulté le 13 octobre 2020. URL : http://journals.openedition.org/ encyclopedieberbere/842; DOI : https://doi.org/10.4000/encyclopedieberbere.842

Ce document a été généré automatiquement le 13 octobre 2020

(c) Tous droits réservés 


\section{Ain SefraA122. AIN SEFRA}

\section{G. Camps}

1 Chef-lieu d'une daïra de 26000 habitants, dans les Monts des Ksours (Algérie), Aïn Sefra, dominé par le Mont Makter, est célèbre par ses dunes d'une couleur éclatante, en partie fixées aujourd'hui. La ville moderne, maintenant réunie à l'ancien ksar, a gardé l'aspect d'une ville de garnison, ce qu'elle est encore.

2 Le pays n'eut jamais de ressources importantes. La principale production est l'alfa* dont l'exploitation suscita très tôt la construction d'une voie ferrée métrique qui atteignit Aïn Sefra dès 1887. Cette ligne fut prolongée jusqu'à Béchar (1906) et Kanadsa, à la fois pour des raisons économiques et stratégiques. Cette voie de pénétration avait été retenue comme la tête du Transsaharien dont le projet ne fut jamais totalement abandonné.

3 Les semi-nomades de la steppe qui se sédentarisent de plus en plus et les nomades sahariens viennent estiver sur les versants, plus frais el plus riches en eau, des Monts des Ksours ; de maigres pâturages subsistent en effet pendant l'été dans les vallées qui entaillent la barrière gréseuse de l'Atlas. Les déplacements de troupeaux se font de plus en plus en camion et les familles elles- mêmes utilisent des camionnettes pour changer de campement. C'est un spectacle inattendu que de voir ces chargements comprenant les ustensiles domestiques, les tentes roulées, les couvertures et tapis, le tout plus ou moins bien arrimé sur lequel sont juchés les femmes et les enfants.

4 Les ksouriens sont des sédentaires qui vivent difficilement de leurs cultures irriguées. La production de dattes, de qualité médiocre et en quantité insuffisante, ne peut alimenter le négoce; les autres cultures vivrières des petites oasis atlasiennes suffisent tout juste à nourrir une population qui ne trouve que dans l'émigration les ressources complémentaires indispensables. 
Les stations rupestres de la région d'Aïn Sefra 1 Rocher Carmillé (Djebel Mahisserat) ; 2 et 3. Stations de Tiout nord et sud ; 4 . Hassi Sliman ben Moussa ; 5 et 6 . Moghrar Tahtani nord et sud ; 7. Djenine bou Rezg ; 8. El Hadj Mimoun ; 9 . Oued Lar'ar ; 10 et 11. Oued Dermel ; 12. Hdra M'Guil.

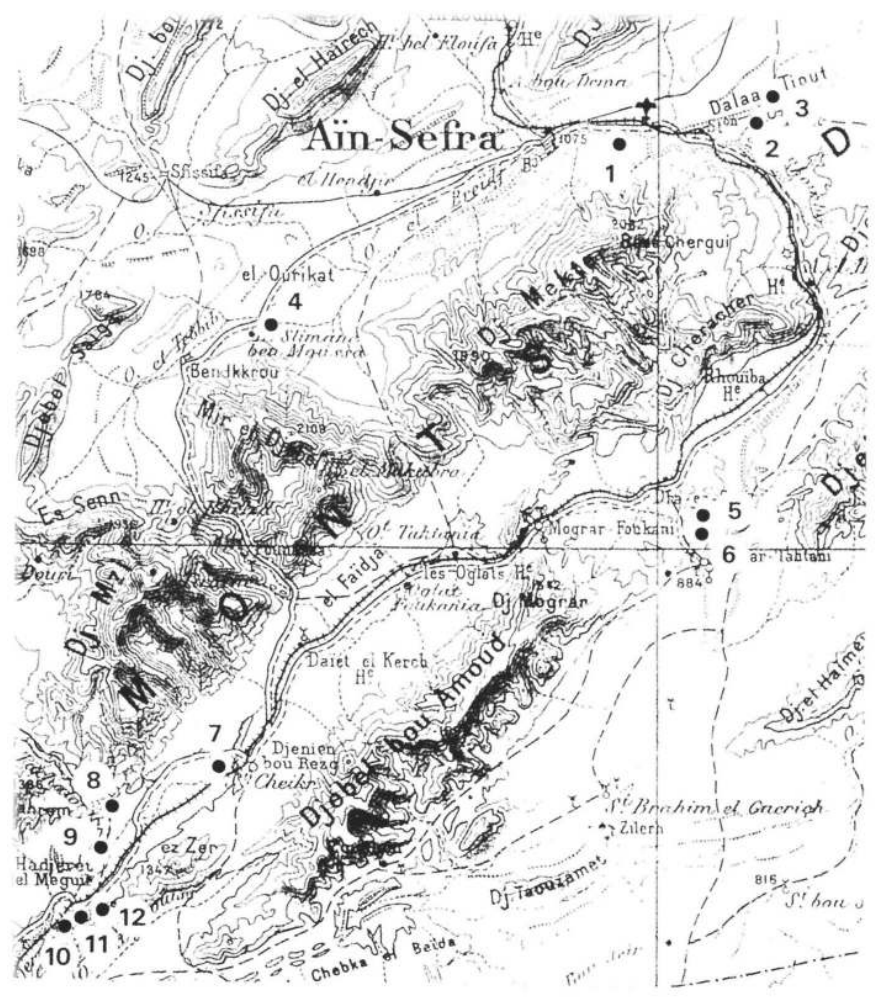

5 Cette émigration se fait vers les cités administratives: El Bayadh à l'est, Aïn Sefra à l'ouest, elle se fait aussi vers le Tell et, depuis 1945, vers la France. Cette émigration, même lorsqu'elle est suivie de retours, a achevé de faire disparaître les rares groupes berbérophones recensés au début du siècle dans certains ksours: Tiout, Bou Semghoum, Moghrar. Le ksar d'Aïn Sefra fut, en revanche, toujours arabophone.

La région d'Aïn Sefra est riche en stations d'art rupestre. A cinq km à l'est, en bordure de la route d'El Bayadh, se situent les gravures du Djebel Mahisserat, connues sous le nom de station du Rocher Carmillé (devenu dans les éditions successives du Guide bleu rocher Carminé, 1950, puis rocher carminé, 1974). Ces gravures représentent une file d'éléphants dont les oreilles sont stylisées (oreilles «bilobées ») ; ils sont précédés d'un lion. Plus importante est la station de Tiout* (orthographiée parfois Thyout), à $16 \mathrm{~km}$ à l'est d'Aïn Sefra, sur la même route. Ces gravures sont les premières au monde à avoir été signalées comme des œuvres préhistoriques (1847). Sur une vaste paroi relativement lisse se pressent en grand nombre des bovins, de grande taille et des lions dont le corps a été soigneusement poli ; entre ces grandes figures se sont glissés des sujets de petite taille. Au voisinage, une autre station (Tiout sud) connue depuis une vingtaine d'années seulement représente des équidés sauvages.

Il faut signaler encore, mais à une plus grande distance d'Aïn Sefra, des stations importantes comme celles de Moghrar-Tahtani*, à une cinquantaine de $\mathrm{km}$ au sudouest, et plus à l'ouest encore les nombreuses stations de l'oued Dermel.

Toutes ces gravures n'ont pas le même âge, bien qu'elles remontent pour la plupart au Néolithique. On s'accorde généralement à reconnaître, parmi les plus anciennes, les figures les plus grandes et les plus réalistes; c'est le style qualifié de «bubalin » par H. 
Lhote et de "grand style naturaliste" par G. Camps; mais il semble qu'en plusieurs stations de l'Atlas saharien, ces grandes figures aient été précédées de représentations aussi réalistes mais gravées plus finement et dans des dimensions plus réduites. D'autre «styles » sont plus récents (voir «Art rupestre »). Des animaux domestiques, tels que les « béliers à sphéroïde ${ }^{*}$, sont représentés dès la phase la plus ancienne de cert art de l'Atlas saharien qui ne peut, donc, être antérieur au $\mathrm{VI}^{\mathrm{e}}$ millénaire. Les tumulus et bazinas* si nombreux dans la région sont beaucoup plus récents.

\section{BIBLIOGRAPHIE}

DESPOIS J. L'Atlas saharien occidental d'Algérie. Mélanges Raoul Blanchard, Québec, 1959, p. 403-415

DESPOIS J. et RAYNAL R. Géographie de l'Afrique du Nord-Ouest. Payot, Paris, 1967, 570 p.

DESSIGNY Cap. Notice sur quelques monuments de la région d'Aïn Sefra. Bull, du Comité des Trav.

hisf. et Scientif. 1908, p. 63-86.

GAUTIER E.-F. Etudes d'Ethnographie saharienne. L'Anthrop., t. XVIII, 1907, p. 37-68 et 315-322.

PETIT Cap. Note sur les tumuli d'Aïn Sefra. Bull, de la Soc. de Géogr. et d'Archéol. d'Oran, t. XXV, 1905, p. 285-295.

Voir Art rupestre, Béliers à sphéroïde, Tiout, Moghrar-Tahtani.

INDEX

Mots-clés : Antiquité, Art rupestre, Géographie 